\title{
English for Biomedical Engineering: Higher School of Technical Education Students as a Case Study
}

\author{
Toufik El Ajraoui, PhD \\ Mohamed V University, Morocco
}

Doi:10.19044/esj.2019.v15n14p1 ～URL:http://dx.doi.org/10.19044/esj.2019.v15n14p1

\begin{abstract}
The teaching of English for Biomedical Engineering (EBE) is regarded as one of the most pertinent developments in English language pedagogy. This paper is an attempt to shed light on the experience of teaching EBE to engineering students enrolled at ENSET (Higher School of Technical Education) in Rabat, Morocco. Since the launching of biomedical engineering stream at ENSET, EBE has been concerned with satisfying the students' expectations and needs by means of a skills-based textbook. In this syllabus the skills range from coping with input texts, such as listening to lectures or tutorials, to producing output texts, such as speaking in realistic situations. Therefore, this investigation aims to measure the adaptability and success of the textbook's key academic skills through a questionnaire that was devised for ENSET students of biomedical engineering. Based on a statistical data analysis, the results revealed that with such a need based language syllabus the target population could benefit from an awareness of the skills and strategies that helped them get the most out of listening and reading materials and produce spoken and written work of high standard. Yet, the respondents noticed that the textbook is challenging and lexically driven as it heavily relies on terminology used in biomedical fields.
\end{abstract}

Keywords: English for Biomedical Engineering, skills-based syllabus, input and output texts.

\section{Introduction:}

Moroccan graduates from various science and engineering majors face ever increasing challenges and difficulties in their integration in the job market due to global recruitment requirements, their inadequate linguistic competence, their weak communication and presentational skills, and their complete reliance on French (El Kandoussi, 2017). Therefore, it is evident that mastering the English language has become "a global literacy skill, a commodity for communication and a vehicle for knowledge transfer" (Modh 
Sidek, 2012, p. 27). English for Specific Purposes (ESP), and by inclusion English for Biomedical Engineering (EBE), aim to meet the learners' specific needs, "relate in themes and topics to a particular field of study, be selective as to language content, and be restricted to the language skills needed in the students' area of specialization" (Strevens, 1978, p. 4).

ENSET (Higher School of Technical Education) took these needs and wants into account when its department of languages and communication first planned and then implemented a skills-based syllabus that was specifically devised for the students of biomedical engineering. In their EBE course, materials played a crucial role in confronting them with language used in biomedical sciences. Accordingly, the major source for them to internalize input was their course book, English for Biomedical Science in Higher Education Studies by J. Chrimes, and their teacher's language resources practiced in the classroom. Because material is a real determiner of the content and nature of the procedure of learning and teaching of this course, the target students' attitude towards their course book was measured through a research tool, namely a self administered questionnaire that constituted the main instrument for qualitative and quantitative data collection. The main purpose of this inquiry is to measure the suitability and success of the textbook's skillsbased approach which basically focuses on receptive skills, reading and listening, to activate productive skills, writing and speaking.

\section{Conceptual Framework:}

Before proceeding to the study, it is necessary to track the following concepts in the literature, namely skills-based syllabus, the role of input and output texts in syllabus design, and learners' attitude towards English for Biomedical Engineering syllabus.

\subsection{Skills-Based Syllabus: The Role of Input and Output Texts:}

In English language teaching, the term skill refers to the specific way to using English combining both structural and functional ability of exact language settings or situations. Thus, skill is the learner's ability to use the target language adequately independently of the context where the language use can occur. In the context of EBE, skills-based syllabus prepares engineering students for the "different skills they will need in their professional future with a great variety of communicative and motivating activities and tasks" (Vera-Cazola, 2015, p. 185). It is the need to develop not only English for specific purposes materials in general terms but also EBE material that suits learners of a biomedical engineering career focus. In this vein, EBE teachers use "contexts, texts and situations from the students' subject area" (Danaye Tous \& Haghighi, 2014, p. 57). This kind of syllabus allows them to devise authentic tasks and "get students doing things with the 
material that they actually need to their work" (Ibid). They see how the four skills, specifically reading, listening, speaking, and writing, can be integrated and exploited effectively in appropriate contexts that can involve learners in genuine and realistic tasks and increase their motivation level. As Sheldon (1988) argues, these syllabi are structured in such a way that the exercises and units are connected and based on situation, theme, topic, and pattern of skill development. Focus, which resides on receptive skills, reading and listening, to activate productive skills, writing and speaking, emanates from what a biomedical engineering student needs to study the target discipline. Tajeddin (2005) conceives ESP textbooks "in terms of three aspects, namely linguistic input, linguistic output and their relationship to each other" (Nezhad \& Atarodi, 2013, p. 54). Likewise, Mc Donough and Shaw (2003) point out that the integrated skills materials should enable learners to see how the four skills can be used effectively in appropriate contexts. Othman (2005) argues that students ranked speaking and writing as the most important skills. In addition, Kwok (2004) recognizes the need to develop oral and written communication skills whereas Cunningsworth (1995) suggests that the four skills are equally important though Othman (2005) states that speaking is one of the most needed skills for engineering students. Thus, developing speaking skill is essential for students majoring in engineering because "the materials for spoken English should equip learners for real life interaction like participating in seminars and listening to lectures" (Danaye Tous \& Haghighi, 2014, p. 65).

\subsection{Learners' Attitude towards the EBE Syllabus:}

Learners' attitude towards ESP textbooks, including EBE textbooks, is a "predictor of attitude towards learning English" (Rahimi \& Hassani, 2011, p. 66). Garinger (2002) and Richards (2001) argue that this finding highlights the role of teaching materials in language courses and adds another advantage to devising textbooks in language classes, namely boosting students' motivation and positive attitude. For Rahimi and Hassani (2011), their motivation and attitude are basically due to the textbook authentic material which "challenges their cognitive abilities and engages them personally" (p. 71). Many researchers like Nunan (2000) and Karahan (2007) believe that the failure or success of learners ascertains with their attitude and skills and that positive language attitudes let students "have positive orientation towards learning English" (Salehi, Khadivar, \& Mehrabi, 2015, p. 97). As Hutchinson and Waters (1987) and Strevens (1988) maintain, the learner's position and reason, which can be educational or professional, define the approach to language teaching, which is in this context geared toward English for biomedical engineering, as to content and method in order to meet the specified demands of engineering students. Moreover, students who are learning English for the purposes of studying science and technology are likely to have a high degree 
of motivation and integration if the textbook or "materials they are using in their English language courses have a scientific and technological content and exhibit the distinctive features of science and technology" (Mansouri, 2010, p. 18). According to Wilson and Yang (2007), this syllabus should reach out to the learners' orientations, choices and aspirations. Thus, its components should be "challenging, interesting, and usable to call their attention and motivate them to learn through their interaction" (Danaye Tous \& Haghighi, 2014, p. 57). As it is discussed below, the field inquiry brings these ideas into light and tests their validity in relation to the specific context and conditions under investigation.

\section{Methodology:}

This section aims to describe the methodology followed in this article. The concepts discussed in this study, namely skills-based syllabus, input and output texts, and receptive and productive skills, are established in the practices experienced in the context of English for Specific Purposes. This field inquiry features the effectiveness of a skills-based syllabus in equipping engineering students with the necessary tools and terminology to cope with the specialized language used in biomedical sciences. Thus, the research questions can be stated as follows:

- What is the importance of the target skills-based syllabus in the language learning process of ENSET students of biomedical engineering?

- What is the respondents' attitude towards the content, skills, and form of the target ESP course book?

In the framework of these research questions, a quasi experimental design serves the aims and purposes this field investigation.

\subsection{Quasi Experimental Design:}

As mentioned above, this study is meant to inquire about biomedical engineering students' attitude towards the content, skills, and form of the ESP course book English for Biomedical Science in Higher Education Studies by J. Chrimes. A quasi-experimental design is suitable for such inquiries mainly because of "the nature of the research question, availability of subjects and amount of resources available" (Wimmer \& Dominick, 1997, p. 187). The research questions stated above start with the word 'what'. First, this type of questions, which is well-suited to the quasi-experimental design, aims to "discover, explain or seek to understand, explore a process, or describe the experiences of participants" (Keyton, 2006, p. 67). More specifically, this research question inquires about the respondents' attitude towards the skills based-syllabus devised for their EBE course. Second, quasi-experimentation deals with the availability of respondents especially during their exposure to 
the quasi-experimental treatment. As a case in point, the quasi-experimental conditions the participants went through consisted of responding to a self administered questionnaire immediately after completing a course on English for biomedical engineering. The purpose of this quasi-experimentation was "to do something to participants and observe the effect of what was done" (Baxter \& Babbie, 2004, p. 205). Last but not least, the quasi-experimental design is appropriate for the limited amount of resources available. In this research investigation, the sampling process, which was based on the quasiexperimental concept of availability, involved sixty students, who belonged to the department of biomedical engineering at ENSET and who accepted to respond to a self administered questionnaire.

\subsection{Sampling:}

The sample is a special subset or portion of a population that "consists of all units - people - possessing the attributes or characteristics in which the researcher is interested" (Keyton, 2006, p. 119). The population of interest had specific demographic and psychographic characteristics. For instance, they were young Moroccan males and females who were preparing a vocational degree in biomedical engineering, who belonged to the age category of twenty one to twenty five, and who had gone through preparatory classes or a twoyear university diploma before they enrolled in the target engineering program. They were also homogeneous in terms of their learning experiences and attitudes to English as a foreign language.

Since all sampling decisions are subjective and strategic, I opted for nonrandom sampling, particularly in the form of a convenience sample which was "a collection of readily accessible subjects" (Wimmer \& Dominick, 1997, p. 63). In this convenience sampling, these respondents were selected on the basis of their availability and homogeneity. The sample's availability stemmed from the fact that they belonged to ENSET where they were studying biomedical engineering. In addition, these informants, who volunteered to take part in this research inquiry, were homogeneous as they shared common demographic and psychographic traits. As it is described below, the implemented mixed methods approach or triangulation enabled me to have the freedom of choice when selecting methods, techniques, and procedures of research to best meet the research needs and purposes (Cherryholmes, 1992; Murphy, 1990). In this mixed methods inquiry, both quantitative and qualitative data were used to study the research problem from various perspectives. In fact, Gravetter \& Wallnau (2000) argue that "mixed methods studies have some definite strength; since they include both qualitative and quantitative data, they provide a more complete picture of a situation than would either type of data by itself' (p. 443). The instruments and analytical 
steps followed to learn about the various aspects of the research questions raised in the survey are explained below.

When the course of English for biomedical engineering was completely covered in the spring semester of the academic year 2017 / 2018, sixty $2^{\text {nd }}$ year-ENSET engineering students accepted to participate in this field study. They responded to a self-administered questionnaire which aimed to track the participants' perception about the target ESP syllabus specifically in terms of content, skills, and form. This survey contained eighteen statements based on a five-point Likert scale of frequency where $1=$ excellent, 2 = good, 3 = average, $4=$ below average, and $5=$ unsatisfactory. To observe the inquiry's reliability and validity, the research tool had gone through piloting which involved a similar population of 15 engineering students. This process brought some indispensible modifications to the content and form of the questionnaire. For data collection, the questionnaire was given to the sample population in the middle of the EBE courses which had been programmed for the whole academic year, for the fall and spring semesters. The collected data were codified and processed using SPSS. Data analysis basically went through descriptive statistics determining the frequencies and percentages of the respondents' answers. Their perceptions about the target textbook's content, skills, and form were statistically computed. For a better clarification and understanding of these perceptions about this ESP textbook, the collected data were assigned the following codes:

\section{The Collected Data Codes and Categorization}

\begin{tabular}{|c|c|c|}
\hline F1:Textbook's content & F2: Textbook's skills & F3: Textbook's form \\
\hline $\begin{array}{l}\text { S1: The textbook's aims } \\
\text { correspond with my learning } \\
\text { needs. } \\
\text { S2: The textbook is } \\
\text { comprehensible to me. } \\
\text { S3: The textbook's content is } \\
\text { sequenced on the basis of } \\
\text { complexity. } \\
\text { S4: The textbook contains } \\
\text { adequate recycling and } \\
\text { revision. } \\
\text { S5: The materials are suitable } \\
\text { for my individual study. } \\
\text { S6: The textbook covers the } \\
\text { main vocabulary items } \\
\text { appropriate to my major. } \\
\text { S7: There is variety of topics. } \\
\text { S8: The topics will help me } \\
\text { expand my awareness and } \\
\text { enrich my experience. } \\
\text { S9: The ordering of material by } \\
\text { topics is arranged in a logical } \\
\text { fashion. }\end{array}$ & $\begin{array}{l}\text { S10: The skills of reading, } \\
\text { listening, speaking, and writing } \\
\text { are adequately covered. } \\
\text { S11: The reading passages and } \\
\text { their associated activities are } \\
\text { suitable for my level. } \\
\text { S12: The listening materials are } \\
\text { interesting to me. } \\
\text { S13: The listening material is as } \\
\text { authentic as possible. } \\
\text { S14: The listening material is } \\
\text { accompanied by activities and } \\
\text { questions. } \\
\text { S15: The material for spoken } \\
\text { English is well-designed to } \\
\text { equip me for real-life } \\
\text { interaction. } \\
\text { S16: The writing activities are } \\
\text { suitable in terms of amount of } \\
\text { guidance or control. }\end{array}$ & $\begin{array}{l}\text { S17: The textbook is attractive } \\
\text { in appearance. } \\
\text { S18: The textbook's graphic } \\
\text { illustrations and pictures } \\
\text { motivate me to talk about the } \\
\text { target subject. }\end{array}$ \\
\hline
\end{tabular}


The analysis of the collected data includes 60 valid questionnaires responses, covering 1080 points of view, where 360 points of view relate to $\mathrm{F} 1,420$ points of view concern F2, and 300 points of view pertain to F3. These data were statistically treated using SPSS.

\subsection{Qualitative data:}

Qualitative data which support the collected quantitative data are indispensible to understand the essence of things especially in terms of their traits, meanings, concepts, definitions, and so forth. They are about the what, how, when, and where of things. In fact, the power of qualitative research derives "primarily from its inductive approach, its focus on specific situations or people, and its emphasis on words rather than numbers" (Maxwell, 1996, p. 17). This field study was put through both quantitative and qualitative analyses. Yet, the adopted qualitative analysis, which transcends the statistical numerical evidence, would make it possible to understand why the participants adopted a specific attitude towards the skills-based syllabus. This kind of analysis stems from my experience as a practitioner who has been involved in instructing the sample students English for biomedical engineering using the target textbook.

\section{The Study:}

The results of this field study are reported for the issues under investigation. As it was mentioned above, these results cover both the quantitative and qualitative analyses of the collected data used for the aim of analyzing the effect of a skills-based syllabus on engineering students' development of receptive and productive skills as well as their awareness of the specialist language used in biomedical fields. The findings confirmed the claims that with such a need based language syllabus the respondents could benefit from an awareness of the skills and strategies that helped them get the most out of listening and reading materials and produce spoken and written work of high standard.

\subsection{Results and Analysis:}

Results from the collected data revealed that this skills-based syllabus had a direct effect on the respondents' receptive and productive skills development. As it can be discovered in the visual displays below, these engineering students were convinced that the target textbook had a positive impact on their learning process and on their quest for the specialist terminology needed in biomedical engineering fields. More details concerning the investigated factors are outlined and summarized in the subsequent paragraphs. 


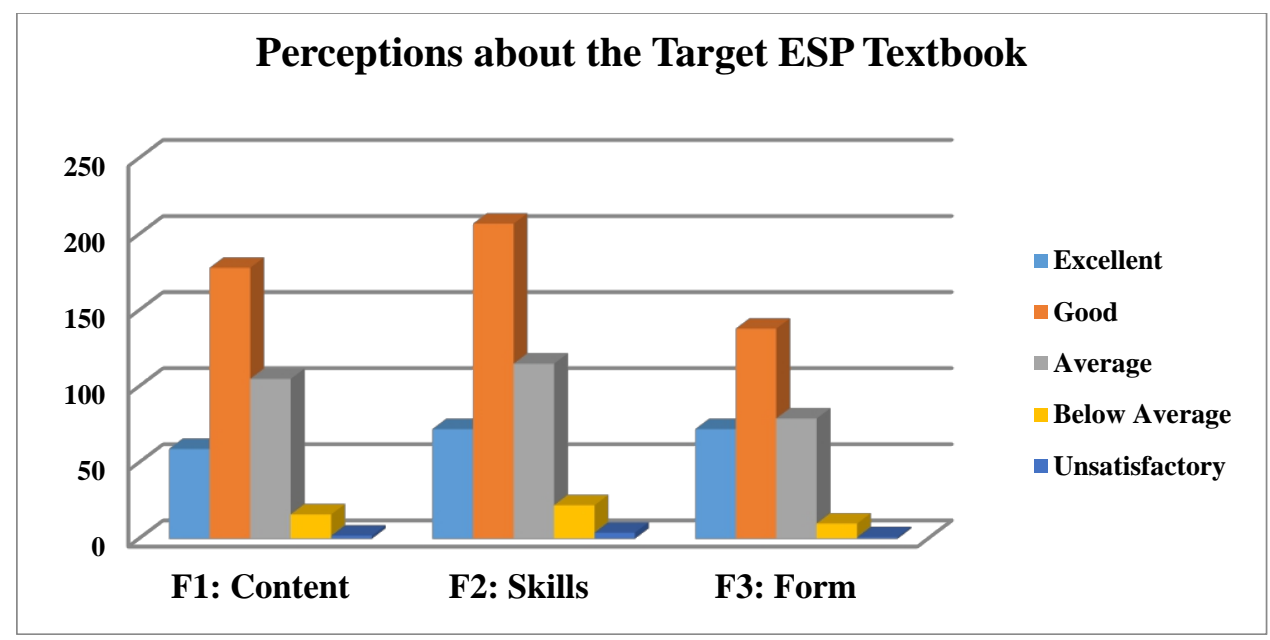

In relation to what Rahimi and Hassani (2011) claim, the respondents' perception about the target ESP textbook was a prognosticator of their attitude towards learning English as whole. They saw their language material as a useful means to achieve progress in their foreign language learning. They were highly motivated and entirely integrated in their English for engineering courses where they used a textbook that has an interesting scientific and technological content, that effectively and adequately exploits the four skills in suitable contexts, and that presents activities and tasks in an attractive form or layout. Generally speaking, the textbook's content suitability especially in topics' selection, ordering, presentation, and grading is proved in the bar chart above. For instance, the majority thought that the textbook's content was good enough for their purposes. In addition, most of the respondents believed that the four skills in the target textbook were well-integrated and equally exploited in appropriate contexts where learners were involved in realistic activities. Concerning the form of the textbook, the participants' feedback was generally positive since they considered that the textbook's items, units, components, and tasks were well-designed, attractive, and clear. The textbook's layout and appearance was appropriate for the general purposes and orientations of the language course. More statistical outcomes and details below make it clear about content, skills, and form of this skills based syllabus. 


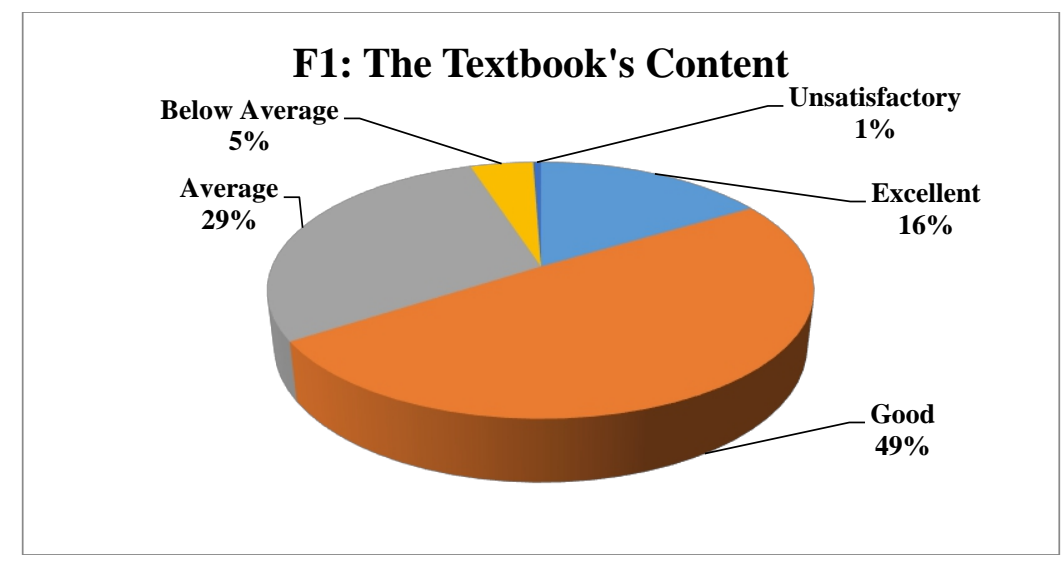

The results above prove that $65 \%$ of the participants had a favorable attitude about the textbook's linguistic input, specifically aims, level, content complexity, content gradation, content suitability, and vocabulary appropriateness. They believed that the syllabus goals correspond with their learning needs as biomedical engineering students who were seeking mastery of English for their academic and professional purposes. For most respondents, the textbook was comprehensible enough to follow its linguistic input. In this sense, they stated that its content was suitable in sequencing complexity, recycling and reviewing items, providing possibilities for further individual practice, and covering important terminology needed for their major. Their positive feedback was due to the various biomedical engineering topics which triggered the learners' cognitive abilities, expanded their awareness, enriched their learning experience, and involved them on a personal basis through personalized vocabulary, issues and themes.

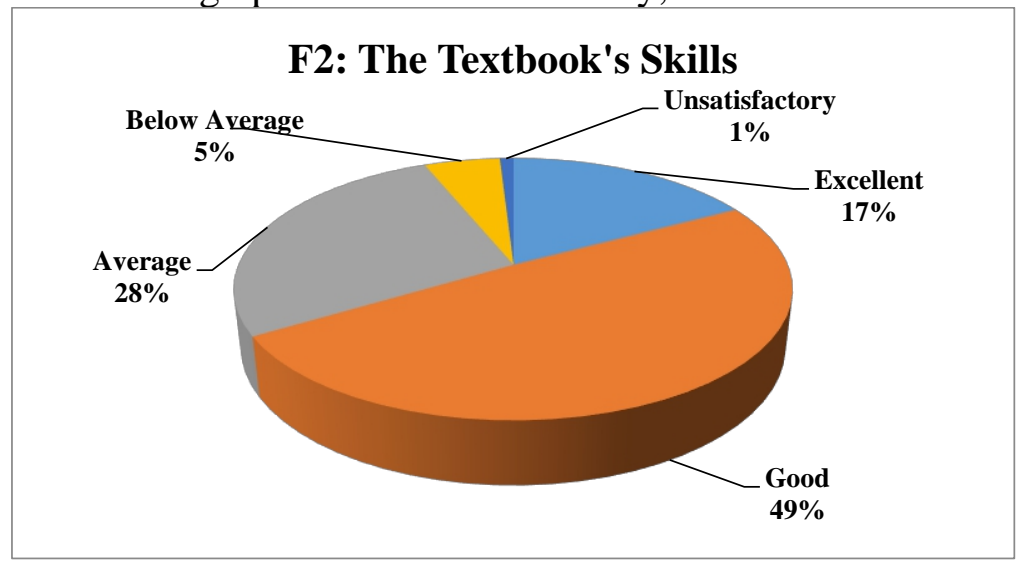

The pie chart above clearly shows that more than half the target population maintained that the four skills, reading, listening, speaking, and writing, were adequately covered. For receptive skills, the respondents claimed that reading 
and associated tasks were suitable for their language level and that listening material and activities were interesting, authentic, and adequately varied. Concerning productive skills, a good portion of participants felt that the material for spoken English was well designed to equip them for real life interaction and that writing activities provided them with sufficient guidance to produce their writing output. This fact was a direct reflection of this skillsbased syllabus which had been devised to suit the learners' academic and career focus.

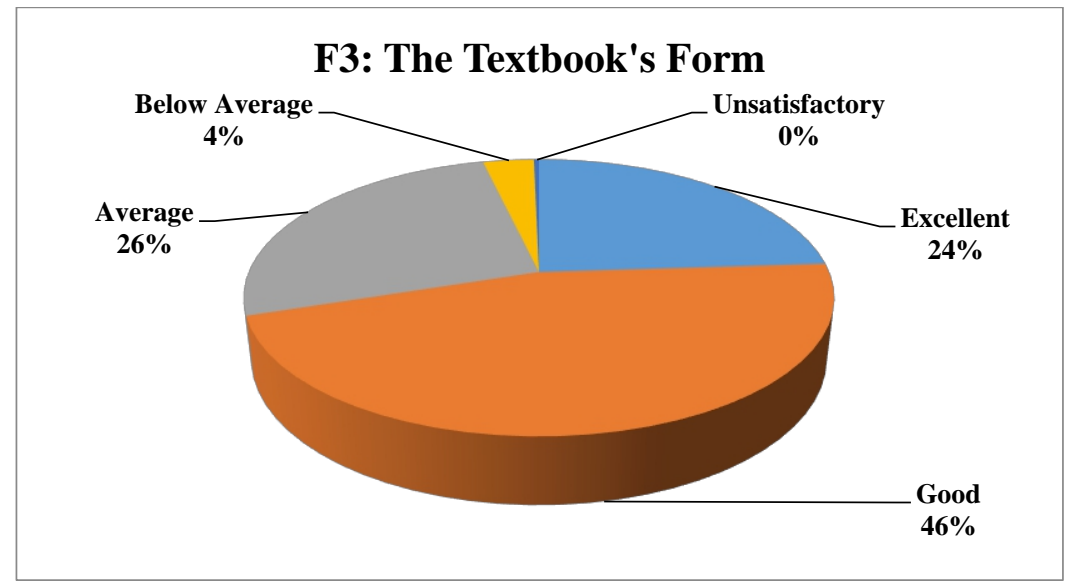

The form of the textbook had a favorable impact on the target population since $70 \%$ of the participants believed that its design and layout was very appropriate for its purposes. The participants agreed that the textbook was appealing in appearance as it differed from other ESP counterparts through the quality of its paper material, real life colors, genuine pictures, scientific graphic illustrations, creative design, and attractive layout which all motivated them to talk and react to biomedical issues and topics.

\subsection{Implications:}

The statistical results above entail several implications. The content of this skills-based syllabus was central to the respondents in terms of its linguistic input, presented in the topics of the reading and listening material, its linguistic output, forwarded by the writing and speaking issues, and its suggested relationship between these two major components. Their positive feedback implies that the topics and issues and the way they relate to each other were conceived as authentic material which triggered the informants' mental abilities and involved them on a personal basis in areas they needed in their field of specialization first as biomedical engineering students and then as professionals. This content, which displayed its distinctive features of biomedical majors, highly motivated learners and closely corresponded with their demands for science and technology. The respondents' answers mean 
that this language content allowed them easy or fluid linguistic integration in academic and professional areas of biomedical engineering.

The importance of the four skills tracked in the students' responses stemmed from what they said about their structural and functional ability especially when they could exploit contexts, situations, and texts directly from their subject area to carry out tasks with the material they really needed in their prospective research projects and career focus. The registered replies proved that the exercises and units were linked in patterns, themes and situations that basically led to a gradual skill development. As mentioned above, the skillsbased syllabus satisfied the respondents' needs to study and work with the target discipline when their textbook focused on receptive skills, reading and listening, to activate productive skills, writing and speaking. The fact that the participants ranked speaking and writing as the most primordial skills means that they had an urgent need to develop their oral and written communication which would definitely equip them for real or genuine specialized English interaction such as conference presentations, research projects, paper defense, professional correspondence, seminars, and meetings.

The participants' reaction to the form of the target syllabus has significant implications. They believed that the experience of using a well designed material with quality paper material, attractive and relevant visuals, suitable layout, and real life photos from their field of specialization was closer to their career expectations and academic orientations. For them, it was material that brought information and enjoyment of an EBE course together with other indispensible variables especially the instructor, the language laboratory facility, and the homogeneous class atmosphere.

Yet, the difficulties raised by the respondents imply that the syllabus was not entirely successful with all the respondents. Some of them, especially those who had lower motivation and insufficient linguistic competence, thought that it was challenging basically in relation to vocabulary or linguistic output which was lexically driven due to the specialized unabridged technical material such as articles, report extracts, genuine lectures, and professional seminars. In fact, this textbook is demanding as it is originally devised for upper-intermediate language learners who must have a linguistic prerequisite to benefit from its assets and qualities.

\section{Conclusion:}

In short, the present inquiry probed into the suitability and success of a skills-based language syllabus for ENSET students of biomedical engineering. The results obtained in the study proved that this EBE material was appropriate for the target learners through the positive feedback that the survey generated. Adopting both a qualitative and quatitative approach to data, the inquiry disclosed a favourable attitude towards this skills-based syllabus 
which basically relies on receptive skills, namely reading and listening, to trigger the learners' productive skills, primarily speaking and then writing. Therefore, these findings can stimulate teachers from all spheres to devise more skills-based syllabi that meet the specific needs and requirements of their various ESP learners who encounter language barriers relating to terminology and academic and / or professional communication. Moreover, the present study has an added value as it aimed to uncover some facts about the teaching of EBE to a sample population of Moroccan engineering students who registered a given feedback collected from their experience with a new ESP textbook. This query for answers highlighted the singularity of this skillsbased syllabus as it offered authentic material in the domain of English for biomedical sciences that can diversify the learners' exposure to field specific language and pave the way for their academic visibility and professional integration. Because the target textbook fostered a solid and balanced link between language input, presented in reading and listening content, and language output, given in writing and speaking tasks, the participants were involved in a process that engaged them in "the transfer of language and knowledge to multiple new contexts" (El Ajraoui, Ben Kaddour, \& Zeriouh, p. 249, 2019). They negotiated and adapted the content of receptive skills activities to reflect and voice their personal experience in productive skills tasks. By and large, this skills-based syllabus positively changed the ENSET engineering students' quest for English language proficiency. Yet, this field investigation might require other queries in different learning contexts to compare the effectiveness of other EBE syllabi devised for Moroccan engineering students.

\section{References:}

1. Baxter, L. A., \& Babbie, E. (2004). The basics of communication research. Belmont: Wadsworth Publishing Company.

2. Cherryholmes, C. H. (1992, August-September). Notes on pragmatism and scientific realism. Educational Researcher, 14, 13-17.

3. Chrimes, J. (2015). English for biomedical science in higher education studies. Reading: Garnet Education Ltd.

4. Cunningsworth, A. (1995). Choosing your course book. Oxford: Heinemann.

5. Danaye Tous, M., \& Haghighi, S. (2014). Evaluation of ESP textbooks: Evidence from ESP textbook of computer engineering major. International journal of research studies in language learning, 3 (2), 55-68.

6. El Ajraoui, T., Ben Kaddour, K., \& Zeriouh, M. (2019). Transversal skills in vocational education and training: The case of ENSAM engineering students. European scientific journal, 15 (8), 237-254. 
7. El Kandoussi, M. (2017). The status of EFL teaching in Moroccan vocational schools: A case study at the Meknès School of Technology. Languages and the market: A ReCLes.pt selection of international perspectives and approaches. Retrieved January 25, 2019 from the World Wide Web: http://www.researchgate.net

8. Garinger, D. (2002). Textbook selection for the ESL classroom. Retrieved October 21, 2016 from the World Wide Web: http://www.cal.org/resources/digest_pdfs/0210garinger.pdf

9. Gravetter, F.J., \& Wallnau, L.B. (2000). Statistics for the behavioral sciences $\left(5^{\text {th }}\right.$ Ed.). Belmont, CA: Wadsworth/Thomson Learning.

10. Hutchinson, T., \& Waters, A. (1987). English for specific purposes: A learning-centered approach. Cambridge: CUP.

11. Karahan, F. (2007). Language attitudes of Turkish students towards the English language and its use in Turkish context. Journal of arts and sciences, 7, 73-87.

12. Keyton, J. (2006). Communication research: Asking questions, finding answers. New York: Mc Graw-Hill.

13. Kwok, M. (2004). Disciplinary differences in the development of employability skills of recent university graduates in Manitoba: Some initial findings. Higher Education Perspectives, 1 (1), 60-77.

14. Mansouri, A. N. H. (2010). Teaching English to students of science and technology. Sino-US English teaching, 7 (2), 17-29.

15. Maxwell, J. A. (1996). Qualitative Research Design: An Interactive Approach (Applied social research methods series: Vol. 41). Thousand Oaks, CA: Sage Publications.

16. Mc Donough, J., \& Shaw, C. (2003). Materials and methods in ELT: A teacher"s guide (2 ${ }^{\text {nd }} \mathrm{Ed}$.). UK: Blackwell.

17. Murphy, J.P. (1990). Pragmatism: From Peirce to Davidson. Boulder, CO: Westview Press.

18. Modh Sidek, H. (2012). EFL textbook analysis. Language and literacy, 14 (3): 27-45.

19. Nezhad, H. Y., \& Atarodi, I. (2013). A checklist-based evaluative and comparative study of ESP books: The case of mechanical engineering. Journal of foreign language teaching and translation studies, 2 (2), 50-69.

20. Nunan, D. (2000). Language teaching methodology $\left(2^{\text {nd }}\right.$ Ed.). Harlow: Pearson Education Ltd.

21. Othman, J. (2005). English language use among EFL learners in Sunway University College. Sunway academic journal, 8 (23), 93-100.

22. Rahimi, M., \& Hassani, M. (2011). Attitude towards EFL textbooks as a predictor of attitude towards learning English as a foreign language. Social and behavioral sciences, 31, 66-72. 
23. Richards, J.C. (2001). The role of textbooks in a language program. Cambridge: CUP.

24. Salehi, H., Khadivar, Z., \& Mehrabi, M. (2015). Evaluation of an ESP medical textbook: Instructors and learners' perceptions in focus. International education studies, 8 (7), 97-107.

25. Sheldon, L. (1988). Evaluating ELT textbooks and materials. ELT journal, 42 (4), 237-246.

26. Strevens, P. (1978). New orientations in the teaching of English. Oxford: Oxford University Press.

27. Strevens, P. (1988). ESP after twenty years: A re-appraisal. In M. Tickoo (Ed.), ESP: State of the art, 1-13.

28. Tajeddin, Z. (2005). The theory and practice of designing a business English course. In G. R. Kiani \& M. Khayamdar (eds.), Proceedings of the first national ESP/EAP conference, 3, Tehran: SAMT Publication, 231-251.

29. Vera-Cazola, M. J. (2015). An analysis of the textbooks for teaching English for medical purposes in the former degree in medicine at the University of Las Palmas De Gran Canaria. Journal of English studies, $13,175-186$.

30. Wilson, K., \& Yang, L. (2007). A social constructivist approach to teaching reading: Turning the rhetoric into reality. China English language education association journal, 30 (1), 51-56.

31. Wimmer, R. D., \& Dominick, J. R. (1997). Mass media research: An introduction. Belmont: Wadsworth Publishing Company. 